\title{
A subsidiariedade como princípio de organização estatal e os reflexos no espaço local: análise do Brasil e da Alemanha*
}

\author{
Recebido: 16 de novembro de 2016 • Aprovado: 30 de julho de 2018 \\ https://doi.org/10.22395/ojum.v18n36a12 \\ Ricardo Hermany* \\ Daniela Arguilar Camargo**
}

\begin{abstract}
RESUMO
O princípio da subsidiariedade é recepcionado no direito em suas modalidades sociopolítica e de organização estatal tendo destaque na Alemanha e sendo compatível no Brasil devido à sua relevância diante da autonomia em âmbito local e lógica cooperativa. Por meio do método de abordagem dedutivo e procedimental bibliográfico, a estrutura do texto parte da análise da subsidiariedade como princípio de organização estatal na Alemanha para, posteriormente, verificar a relação do princípio com o Estado Federal Brasileiro e, por fim, analisar a aplicabilidade no âmbito local brasileiro diante da autonomia municipal, além de destacar os benefícios da inserção desse princípio nas esferas da Federação Brasileira. Ao final, sugere a aplicação de tal princípio na cooperação entre os entes locais, pois a subsidiariedade vem a defender o escalonamento vertical, no qual as competências permaneçam, sempre que possível, no nível menor. E também que os Estados e a União só deverão ceder determinadas competências que eles individualmente não forem capazes de assumir. O princípio é reconhecido como crucial para os governos locais para que possam participar nacionalmente da busca por cidadania e por soluções de interesse local.
\end{abstract}

Palavras-chave: federação; subsidiariedade; organização estatal; município.

\footnotetext{
Este artigo é fruto das pesquisas realizadas pelo grupo de pesquisa Gestão Local e Políticas Públicas vinculado ao Programa de Pós-Graduação em Direito (Mestrado e Doutorado) da Universidade de Santa Cruz do Sul, Brasil.

** Advogado. Doutor em Direito pela Universidade do Vale do Rio dos Sinos, Brasil, com Doutorado sanduíche pela Universidade de Lisboa, Portugal; Pós-Doutor na Universidade de Lisboa, Portugal; Professor da graduação e do programa permanente do Programa de Pós-Graduação em Direito (Mestrado e Doutorado) da Universidade de Santa Cruz do Sul, Brasil. E-mail: hermany@unisc.br. Orcid: https:// orcid.org/0000-0002-8520-9430

*** Advogada. Mestre em Direitos Sociais e Políticas Públicas pelo Programa de Pós-Graduação em Direito da Universidade de Santa Cruz do Sul, Brasil.E-mail: danielacamargo68@gmail.com. Orcid: https:// orcid.org/0000-0002-5370-6969
} 


\title{
Subsidiarity as a principle of state organization and its reflexes in local spheres analysis of Brazil and Germany
}

\begin{abstract}
The principle of subsidiarity is accepted in law in its sociopolitical and state organization forms, being considered a highlight in Germany and compatible in Brazil due to its relevance to local autonomy and cooperative logic. Through the method of deductive and bibliographic procedural, the structure of the text starts from the analysis of subsidiarity as a principle of state organization in Germany, to later verify the relation of this principle with the Brazilian federal state and, finally, to analyze the applicability in the Brazilian local context towards the autonomy of municipalities, and also emphasizing the benefits of the insertion of this principle in different spheres of the Brazilian federation. At the end, it suggests that such a principle be applied in the face of cooperation between local authorities, since subsidiarity is based on vertical scaling, where competences are kept to a minimum. Also, in which States and Union should only yield certain competences that they themselves are not able to assume. This principle is seen as crucial for local governments in order to participate nationally in the quest for citizenship and for solutions of local interest.
\end{abstract}

Keywords: federation; subsidiarity; state organization; county.

\section{La subsidiariedad como principio de organización estatal y los reflejos en el espacio local: análisis de Brasil y Alemania}

\section{RESUMEN}

El principio de la subsidiariedad es recibido en el derecho en sus modalidades sociopolítica y de organización estatal con destaque en Alemania y siendo compatible en Brasil debido a su relevancia frente a la autonomía en el ámbito local y lógica corporativa. Mediante el método de enfoque deductivo y procedimental bibliográfico, la estructura del texto parte del análisis de la subsidiariedad como principio de organización estatal en Alemania para, posteriormente, verificar la relación del principio con el Estado Federal Brasileño y, por fin, analizar la aplicabilidad en el ámbito local brasileño frente a la autonomía municipal, además de destacar los beneficios de la inserción de ese principio en los contextos de la Federación Brasileña. Al final, sugiere la aplicación de dicho principio en la cooperación entre los actores locales, puesto que la subsidiariedad defiende el escalonamiento vertical, en el cual las competencias permanezcan, siempre que posible, en el nivel más bajo. Y también que los Estados y la Unión apenas deberán ceder determinadas competencias que individualmente no sean capaces de asumir. El principio es reconocido como crucial para los gobiernos locales para que puedan participar nacionalmente de la búsqueda por ciudadanía y por soluciones de interese local.

Palabras clave: federación; subsidiariedad; organización estatal; municipalidad. 


\section{INTRODUCÃ̃O}

A origem da subsidiariedade é encontrada na filosofia política e social, e também foi investigada por autores como Aristóteles e Althusius. Posteriormente, foi assimilada pela Igreja Católica, onde se tornou um princípio na Carta Encíclica Quadragesimo Anno (1931), escrita pelo Papa Pio XI, que afirma que a retirada dos indivíduos daquilo que eles podem fazer por iniciativa particular para colocar a confiança na coletividade se trata de uma injustiça.

Em meados de 1950, ocorreram as correntes contraditórias na doutrina da Alemanha em que a Lei Fundamental de Bonn (1949) incorpora o princípio da Subsidiariedade; contudo, é somente no Tratado de Maastricht (1992) que recebe uma configuração e estabelece o tratado de que naqueles domínios em que a competência é concorrente, a comunidade somente poderia realizar uma intervenção quando os objetivos de determinada ação não pudessem mais ser realizados pelos Estados-membros, sendo melhor atendidos pela comunidade diante da sua dimensão ou efeitos previstos.

Por conseguinte, após as reformas constitucionais na União Europeia possibilitouse a constitucionalização desse princípio, que foi inserido na Lei Fundamental de Bonn pela Alemanha, que assim regularizou a sua participação na União Europeia. Essa temática gerou uma nova relação polêmica do princípio para com a federação. Como exemplo, Portugal previu expressamente a aplicação da subsidiariedade como orientador de sua participação e, por ser um Estado unitário descentralizado, estendeu o princípio para sua ordem interna.

Ainda, mesmo que tenha uma função de suplência e justifique a ajuda do Estado, tal princípio também limita uma intervenção de um órgão superior, ou seja, a União não deveria assumir o que os Estados estão capacitados para realizar, igualmente com os Municípios, pois a subsidiariedade procura a junção do federalismo e a solidariedade - uma correlação entre autonomia, integração e cooperação.

No Brasil, diante da luta desenfreada contra a ineficiência de vários setores, a Constituição Federal de 1988 continuou a entregar para a União algumas competências que esta não consegue realizar efetivamente. Aqui é apontado o ideal da subsidiariedade onde pode se tornar uma ferramenta para a reformulação do pacto federativo do Brasil e para a repartição constitucional de competências entre os entes visando uma maior autonomia municipal com respeito às políticas sociais.

A finalidade do estudo é contribuir para a compreensão desse princípio, bem como para a aplicação na organização estatal brasileira, com ênfase no governo mu- 
nicipal, pois se trata de um intermediário entre o indivíduo e o Estado por meio do qual a subsidiariedade resta concretizada, o que explica e justifica uma política de descentralização de poder. A partir disso, surge a seguinte indagação: o princípio da subsidiariedade acarreta um fortalecimento da esfera local tornando-se indissociável e imprescindível para a federação?

Dessa forma, para responder a esse questionamento utilizou-se o método de abordagem dedutivo, pois a resposta se encontra ao longo do estudo, assim como o método de procedimento bibliográfico, sendo que a pesquisa se baseou em diversas obras para a compreensão do tema proposto. Ainda, a estrutura metodológica inicia com o estudo da subsidiariedade como princípio de organização estatal na Alemanha e posteriormente no Brasil para, ao final, apontar os reflexos no âmbito local brasileiro calcado na subsidiariedade.

\section{A SUBSIDIARIEDADE COMO PRINCÍPIO DE ORGANIZACÃO ESTATAL NA ALEMANHA}

O ideal subsidiário surge com o Estado de Bem-Estar na Alemanha, apresentando uma cobertura obrigatória para os riscos sociais (em meados do século 19, a iniciativa de Bismarck com a aprovação no parlamento de um conjunto de leis que visavam a proteção social contra a saúde e acidentes). Diante dessa iniciativa, o Estado alemão passou a ter um executivo mais forte com o equilíbrio da monarquia, representação no parlamento e federação, de acordo com Bertan (2001).

Com a criação da seguridade social que se sobrepôs a algumas instituições que já existiam, de inciativa individual e coletiva, criou-se associações na busca pela proteção aos riscos sociais, sendo esses locais conhecidos como arenas de debates e organização de greves (Palier, 2010). Posteriormente, o período de reconstrução do pós-Segunda Guerra teve como base a economia social, em que os mecanismos da seguridade social trouxeram elementos fundamentais para atuar junto com as forças do mercado em controle do Estado. Esses fatores combinados com a política social, a reconstrução e o crescimento nos chamados anos dourados acomodaram demandas sindicais e democracias cristãs sem confrontos, sendo que as associações e as políticas de consenso se tornaram a base da sociedade cooperativa.

No ano de 1957 ocorreu a reforma da previdência na Alemanha, que trouxe uma correção aos benefícios e introdução de outros com a finalidade de alinhar os padrões de vida dos trabalhadores. Ainda, a reforma de 1972 trouxe uma garantia de seguridade mínima para todos aqueles que eram segurados. Ao final, ficou sendo um welfare state avançado, pois detinha uma cobertura universal dos trabalhadores e benefícios, de acordo com Hockerts (1981). 
Essa contextualização das reformas previdenciárias foi assentada no princípio da subsidiariedade, pois esse princípio remonta à doutrina católica, acarretando para o Estado social a intervenção deste na garantia de diferentes questões sociais que estão entre o Estado e indivíduo, podendo assumir suas próprias responsabilidades. A intervenção estatal deve ser sempre subsidiária, ou seja, um recurso último quando os demais falham, para centrar-se assim no fortalecimento das comunidades alemãs. Tal princípio está alocado na teoria social, em que a sociedade deve se unir, pois estes só fazem algo dentro de um grupo social, como associações e sindicatos, visto que a política social fortalece um grupo e este cuida dos indivíduos, conforme Van Kersbergen (1995). No Estado alemão a subsidiariedade está do lado do Estado minimalista, que se volta para as políticas de assistência e busca promover o bem-estar de outro baseando-se em um planejamento central.

De forma paralela, verifica-se o princípio diante da Lei Fundamental de Bonn (1949), que ensejou diversas controvérsias, ainda mais na década de 1950, quando a orientação de existência do princípio se demonstrou diante do direito constitucional alemão, conforme Götz e Hecker (1999), e que o mesmo possuía a menção à dignidade da pessoal humana, defendida na lei pelos artigos $1^{\circ}$ e $2^{\circ}$, além da proteção da família (artigo 6), livre associação privada (artigo 9º), autonomia administrativa nas comunas (artigo $28^{\circ}$ ) e sistema de repartição de competências (artigos $30^{\circ}, 70^{\circ}$ e $72^{\circ}$ ).

Na busca pela consciência de valores após a Segunda Guerra ocorreu o renascimento do direito natural cristão, no qual uma corrente afirmava o acolhimento do princípio tendo como fundamento a Encíclica Quadragesimo Anno', como entendem Weber e Gas (2000). Pela falta do expresso princípio, os seus defensores o viam dentro da Grundgesetz nos direitos fundamentais e repartição de competências, contudo requeriam que este fosse reconhecido como um valor constitucional, como um princípio da Grundgesetz, disposto por Götz e Hecker (1999).

Contrariamente ao princípio da subsidiariedade na Lei Fundamental, apontam Weber e Gas (2000), que a corrente positivista entendia que a constituinte de 1948 teria negado o acolhimento desse princípio, o que refletiu na fixação de princípios do ordenamento social que seriam concretos. Além do mais, acusavam os defensores do princípio quanto às suas expressões e embora concordassem que havia elementos do princípio na autonomia das comunas e legislação concorrente, negavam tal princípio.

1 Foi promulgada 40 anos após a "Rerum Novarum", em 15 de maio de 1931, pelo Papa Pio XI, em um contexto em que o mundo estava marcado pela Revolução Russa, pela Primeira Guerra Mundial e em meio à crise de 1929. Tinha como ideais básicos: manter a crítica ao socialismo e ao capitalismo e reafirmar a Doutrina Social da Igreja Católica como uma terceira via para o tratamento da questão social e econômica. 
Essa discussão, conforme dispõe Götz e Hecker (1999), não tinha relevância jurídica e foi deixada de lado por 25 anos. Ainda, o Tribunal Constitucional da Alemanha não acolheu o princípio, nem de modo geral nem vinculante, o que deixou questões abertas. De acordo com Clergerie (1997), tal posição foi engajada por seu caráter filósofico e religioso, e resultou em alegações de inconstitucionalidade por violação a esse princípio por meio do Tratado de Maastritcht, que recomeçou esse debate influenciado pelos Länder (Estados Federados da Alemanha), que temiam perder a competência diante da União Europeia.

Após a ratificação do tratado, ocorreu a mudança na Lei Fundamental, em 1992, e criou-se um novo texto ao artigo 23, que dispunha sobre o ingresso e a participação do Estado alemão na União Europeia. Com esse dispositivo, os Länder asseguraram sua força participativa e fizeram com que a subsidiariedade fosse expressa no âmbito da Lei Fundamental.

De acordo com Götz e Hecker (1999), o referido artigo estabelece que nos assuntos da União Europeia, tanto o parlamento federal quanto os Länder participarão dos assuntos por meio do conselho federal, conforme o artigo 23, alínea 2. Ainda, esse conselho participará na formação da vontade do Estado alemão. Devendo o governo federal levar em consideração a opinião desse conselho, quando se tratar de uma competência exclusiva do Estado, pois os Länder podem ser lesados. Já se a causa for as competências legislativas dos Länder, a opinião do conselho deverá ser decisiva na formação da vontade (de acordo com a alínea 5).

Contudo, se a causa for competências legislativas exclusivas dos Länder quanto a questões de educação, cultura, televisão e direitos humanos, esta deverá ser realocada para a federação, por meio de um representante dos Länder, nomeado pelo conselho (artigo 23, alínea 6). Ainda, a importância da subsidiariedade está no texto do artigo 23, pois este destaca que a Alemanha deve colaborar com o desenvolvimento da União Europeia, e que esta está vinculada a princípios federativos, sociais e democráticos, e também aos princípios da subsidiariedade e da proteção de direitos fundamentais dispostos na alínea 1. O artigo estabelece meios para que a União Europeia seja construída pela visão alemã, incluindo o princípio federativo e da subsidiariedade.

Artikel 23 - (1) Zur Verwirklichung eines vereinten Europas wirkt die Bundesrepublik Deutschland bei der Entwicklung der Europäischen Union mit, die demokratischen, rechtsstaatlichen, sozialen und föderativen Grundsätzen und dem Grundsatz der Subsidiarität verpflichtet ist und einen diesem Grundgesetz im wesentlichen vergleichbaren Grundrechtsschutz gewährleistet. Der Bund kann hierzu durch Gesetz mit Zustimmung des Bundesrates Hoheitsrechte übertragen. Für die Begründung der Europäischen Union sowie für Änderungen ihrer vertraglichen Grundlagen und vergleichbare Regelungen, durch die dieses Grundgesetz seinem Inhalt nach geändert 
oder ergänzt wird oder solche Änderungen oder Ergänzungen ermöglicht werden, gilt Artikel 79 Abs. 2 und 3.2 (Grundgesetz, 1949)

O princípio da subsidiariedade no Estado alemão firma a relação entre ele e a União Europeia, contudo não soluciona os conflitos dentro de sua extensão. Aqueles que defendem o princípio entendem que no artigo 23 da Lei Fundamental, há argumentos suficientes para a aplicação interna do princípio. Isso pode ser verificado sobre dois pontos, colocados por Götz e Hecker (1999): primeiro, por meio da repartição das competências entre a federação e seus Estados (Bund x Länder); segundo, pela repartição das competências concorrentes.

A Federação Alemã está voltada para a repartição das competências concorrentes, conforme disposto no artigo 72 e 74, onde temos controvérsias com o reconhecimento da subsidiariedade e sua contribuição para a Alemanha. O referido artigo foi alterado em 1994 pela Lei Federal 42 e em 2006 pela Lei Federal 52, o que demonstra que as competências concorrentes são de grande interesse atualmente em função da unificação e dos impactos da União Europeia, bem como da preponderância da legislação alemã.

Diante disso, a alínea 2 do artigo 72, continua com o critério da necessidade que equivale a subsidiariedade e esses fatores apresentam matrizes distintas daqueles positivados no direito comunitário. Na atuação das comunidades fica amparada a necessidade da atuação de incapacidade do Estado-membro por meio da dimensão dos efeitos da ação. Além disso, o papel da federação leva em consideração a necessidade de condições de igualdade em seu território, bem como a salvaguarda jurídica e econômica dos interesses comuns e conjuntos. Tal consideração foi feita por Quadros (1995) e entende que o federalismo da Alemanha não está devidamente organizado com a subsidiariedade.

Ao final, verifica-se que a subsidiariedade tem, de forma expressa, a aplicação no Estado alemão e na União Europeia, por meio do artigo 23 da Lei Fundamental alemã, sendo que sua aplicação internamente ainda é controversa, mesmo que admitida de forma implícita na repartição das competências legislativas concorrentes (Bund

2 Tradução própria: Artigo 23 - alínea 1: Para a realização de uma Europa unida, a República Federal da Alemanha contribuirá para o desenvolvimento da União Europeia, que está comprometida com os princípios democráticos, de Estado de direito, sociais e federativos e com o princípio da subsidiariedade e que garante uma proteção dos direitos fundamentais, comparável em sua essência à garantia constante nesta Lei Fundamental. Para tal, a Federação pode transferir direitos de soberania através de lei com anuência do Conselho Federal. Para a criação da União Europeia, bem como para as alterações dos tratados constitutivos e de todas as normas correlatas, através dos quais esta Lei Fundamental venha a ser modificada ou complementada em seu conteúdo ou que ensejarem tais mudanças ou complementações, aplica-se o artigo 79 §2 e 3. 
x Länder) e na aplicação dos fatores ora positivados pela União Europeia, diante do artigo 72 da referida lei.

A subsidiariedade na Alemanha, no âmbito interno, significa que as responsabilidades públicas devem ser regulamentadas pelos cidadãos, quando for possível, no sentido de que os problemas devem ser resolvidos no menor nível político, ou seja, nos Municípios. Com base nisso, de uma forma mais abrangente, naquilo em que o indivíduo não consegue realizar por sua conta própria, pode receber auxílio, se solicitado à sua comunidade, Município, consórcio, associação, Kreis, Estado ou União, respectivamente. De forma a garantir que determinada competência e responsabilidade de cada esfera da vida seja reconhecida e efetivamente concretizada.

Esse princípio atua como um ordenador de distribuição de poder e tem como ponto de partida os Municípios, de acordo com Carneiro (2012). Na Alemanha, a sociedade, por meio das associações, entre outros grupos, assume boa parte das tarefas em prol do bem comum, já que se entende esse fato por subsidiariedade em sentido horizontal. Ainda conforme o autor, nos países anglo-saxões, muitas vezes a presença do Estado é solicitada pela população e os governos locais são os primeiros a serem chamados por meio das políticas públicas, devido ao fato de estarem mais próximos aos cidadãos.

\section{A FEDERACÃO BRASILEIRA E A SUBSIDIARIEDADE}

Diante da descentralização que é comum na aplicação da subsidiariedade, esta possui aplicabilidade na federação, pois se demonstra como um instrumento de ajuste para a especificidade dos interesses, bem como das ações eficazes. Compreende Baracho (1997) que o dinamismo do federalismo se relaciona com a subsidiariedade e mostra a relação da integração com a autonomia, criando uma subsidiariedade nos pilares federativos com a capacidade de assegurar paz e liberdade para os Estados.

Zimmermann (1999) teve como objetivo investigar a federação e a necessidade de um poder central, bem como o reconhecimento da finalidade e da distribuição das competências entre os entes federados. Segundo o autor, tais questões são pertinentes para a delimitação da autoridade de governo e para que esta fique submetida às regras do Estado de Direito, com o controle social dos atos.

Ainda conforme Baracho (1997), diante da aplicabilidade desse princípio, entendese que este se torna aplicável quando a ordem e o poder possuem limitações, de maneira que se equilibra a liberdade e detém o poder intervencionista do Estado, indevido em muitas áreas da sociedade, o que possibilita à União o controle e a coordenação das atividades no pluralismo social. Ainda conforme evidenciado pelo 
autor, determinado princípio não tem como finalidade a destruição das competências dos Estados, mas sim uma ordenação responsável.

A função subsidiária, diante de um princípio de competência, ao ser transferida para as comunidades e aos Estados, é considerada como um princípio divisor de poder e confere à cada comunidade o necessário para a execução de seu papel. Gonçalves (2003) elucida que a função subsidiária se torna aplicável em regulamentações das relações de poder e serve como escalonador das atribuições para o entendimento dos interesses coletivos, o que obriga a redefinir os níveis de atuação social, estatal e individual, diante da prossecução dos interesses individuais. Dispõe ainda que esse princípio valorizou a autonomia individual e dos grupos, além de fomentar o expansionismo das capacidades dos entes menores, por meio da ação dos maiores ao promoverem a repartição das competências entre o Estado e a Sociedade.

O fundamento da subsidiariedade é encontrado, conforme Gonçalves (2003), no indivíduo, pois Aristóteles já entendia que qualquer homem detém a capacidade de realizar suas necessidades. Ainda, a sociedade por ele descrita é composta por grupos que exercem tarefas específicas para responder àquelas necessidades insatisfeitas.

Em primeiro plano, o princípio da subsidiariedade não ganhou em nenhum momento uma expressa menção dentro de alguma Constituição do Brasil, em nenhuma das modalidades sociopolítica ou de organização estatal. Diante da repartição de competências, a Constituição de 1988 continuou entregando para a União, competências que muitas vezes esta não consegue realizar com plena efetividade, sendo que o objeto da subsidiariedade, que serviria como um modo de reformulação do pacto federativo, não foi utilizado.

Em um breve histórico, o Brasil inspirou-se na federação norte-americana e inaugurou um governo provisório. Contudo, uma diferenciação que merece evidencia é que no tempo em que os Estados Unidos optaram por um federalismo por agregação, no qual os Estados são soberanos e se encontravam constituídos e organizados por suas Constituições, o Estado brasileiro evidenciou um federalismo por segregação, no qual as federações não soberanas foram criadas por intermédio do poder central, conforme disposto por Ferraz (1979).

A Constituição de 1981 passa a adotar um sistema de repartição de competência entre os entes, conhecido como "federalismo dual", que foi inaugurado pela Constituição Norte-Americana e apresenta uma separação das competências, já que atribui umas exclusivas e outras remanescentes aos Estados-membros, evidenciado pelo artigo $34^{\circ}$ e $65^{\circ}$ da referida Constituição. Diante da repartição de competências, os poderes que foram concedidos não estavam somente nas mãos do poder central. 
Já na Constituição de 1934, conforme aponta Horta (2002a), ampliou-se a organização dos poderes no sistema federal e relevou-se competências materiais e legislativas atribuídas aos entes. Ainda, em Almeida (2005) são evidenciados dois fenômenos relacionados a essa Constituição: o aumento dos poderes federais e a implantação do chamado "federalismo cooperativo".

Com a Constituição de 1937, obtivemos o acolhimento dos elementos do federalismo, em que o sistema de repartição de competências sofre alterações em seu papel centralizador e permite que os Estados participem da legislação concorrente. Ainda, o texto constitucional de 1946 adota a legislação concorrente, contudo não especifica as competências de cada ente, além disso, não previu competências comuns. Esse emblema deu origem à Constituição de 1967, por meio da qual a organização federal demonstra uma tendência centralizadora. E posteriormente, a Emenda à Constituição de 1969, que colocou uma decisão ao poder central e incorporação direta de disposições que já estavam na Constituição dos Estados.

Ainda, com o intuito de interação da nação, o federalismo foi além do cooperativo, e atribuiu poderes para a União diante da política nacional, o que evitou conflitos com os entes e promoveu o desenvolvimento econômico para a coletividade.

O princípio da subsidiariedade, na Constituição vigente, enumera em seu artigo $1^{\circ}$ os princípios fundamentais da Federação Brasileira, entre eles, a autonomia, a cidadania, os valores sociais do trabalho, a dignidade da pessoa humana, a livre iniciativa e o pluralismo político. Conforme o entendimento de Nunes (2002), esses princípios são a estrutura jurídica e devem ser estritamente obedecidos; já para Mello (1996), eles são considerados como mandamentos. Nessa senda, verifica-se que a subsidiariedade tem vinculação com todos os princípios fundamentais, em destaque para a forma do Estado e dignidade da pessoa humana, uma vez que este tem como fundamentação a autonomia individual. Com esse entendimento, Horta, citado por Maciel (2004), compreende que os dispositivos que experimentam a subsidiariedade são os artigos $23^{\circ}, 197^{\circ}, 198^{\circ}, 205^{\circ}, 206^{\circ}, 225^{\circ}$ e $227^{\circ}$, e reconhece ainda que este tem reconhecimento nas Constituições Brasileiras.

No caso específico do federalismo Brasileiro, a preexistência da competência supletiva ou complementar, prevista nas Constituições Federais de 1934, 1946 e 1967, e da competência da legislação concorrente ou mista, adotada na Constituição de 1988, com explicitação enumerada de suas matérias, localizadas, as formas pretéritas da competência supletiva ou complementar, e a forma contemporânea da legislação concorrente ou mista, na área da repartição de competências da Federação, por equivalência da legislação supletiva ou complementar, anteriormente, e da legislação concorrente, atualmente, com os objetivos e finalidades do princípio da subsidiariedade, concluo pela desnecessidade, em tese, da atividade do poder constituinte de revisão, para introduzir no texto constitucional Brasileiro o princípio constitucional 
da subsidiariedade, considerando a equivalência entre o princípio e a legislação concorrente, dotada de natureza subsidiária, complementar e supletiva. O princípio da subsidiariedade projetou-se na autonomia da subsidiariedade constitucional, dispensando tratado ou a Revisão. (Maciel, 2004, p. 46)

A aplicação desse princípio, conforme já evidenciado, serve para a proteção de direitos fundamentais diante da tendência centralizadora presente na política nacional. Maciel (2004) ainda entende a subsidiariedade como credora dos princípios da proporcionalidade e da razoabilidade.

Por conseguinte, merece destaque a consideração de que as Constituições de 1934 e 1946 são anteriores à Lei Fundamental da Alemanha de 1949. Além disso, a Lei fundamental estabeleceu a prevalência dos Länder no âmbito da legislação concorrente, em que o direito de legislação diante da federação deve ser realizado quando há a necessidade de regulamentação da lei federal diante de determinados fatos.

Nesse sentido, Ricardo Hermany compreende a partir do estudo do sistema constitucional português que é possível aplicar a subsidiariedade no Brasil, e enfatiza que "É essencial que o poder local se estruture no sentido de consagrar a ideia de subsidiariedade, seja em relação à atribuição de competências à esfera local, seja na modificação estrutural do próprio poder local". (Hermany, 2005, p. 1403). Além do mais, conforme o autor, a concepção de subsidiariedade quando inserida na constituição portuguesa permite que "se constitua uma nova estrutura na formação das decisões públicas, deixando de repetir em nível local as estratégias tradicionais, caracterizadas pela subordinação". (Hermany, 2005, p. 1403).

E com relação às competências, o princípio, conforme o autor, mostra-se fundamental, tendo em vista a vinculação das atribuições dos Municípios ao conceito indeterminado de interesse local. Assim, a subsidiariedade serviria como um delimitador na atuação desse ente além de permitir que "um maior número de atribuições seja gerido a partir da esfera local, sempre que exista um interesse, ainda que não exclusivo, por parte dos cidadãos do Município", (Hermany, 2005, p. 1403).

A subsidiariedade se expressa de maneira em que o que pode ser feito por uma sociedade não deve ser realizado por um ente maior e traz a ideia da supremacia da sociedade diante do Estado, o que coloca o poder público diante do poder de decidir, sendo evidente a adoção desse princípio no ordenamento do Brasil quando este se legitima por meio da descentralização política, da repartição de competências e das iniciativas privadas e comunitárias. A análise da subsidiariedade na Constituição de 1988, mesmo não estando expressa, desencadeou uma implantação do federalismo com maior equilíbrio e agora deve ser analisada a autonomia dos entes federados para compreender as reflexões da subsidiariedade no âmbito municipal. 


\section{REFLEXOS NO ÂMBITO MUNICIPAL BRASILEIRO CALCADO NA SUBSIDIARIEDADE}

No Estado alemão, a municipalização se dá por uma série de cumprimentos e é observada por meio de uma teoria democrática superior, tendo em vista que os cidadãos e o seu ambiente o afetam exclusivamente. Assim, conforme Merk (2013), do ponto de vista de desempenho, é o espaço com maior eficiência e eficácia das ações administrativas, como competências destinadas aos níveis locais, o que permite um melhor conhecimento das necessidades locais, assim como dos resultados e das peculiaridades para uma melhor alocação de recursos.

Os argumentos tradicionais referentes à subsidiariedade na Alemanha vêm de administrações nas quais o governo provincial reformista apresentou um argumento dos grupos de interesse locais, no sentido de um maior fortalecimento dos conselhos distritais e Municípios. As reformas, realizadas nos anos de 2005 e 2006, atingiram a cooperação entre governos e atores políticos locais. No ano de 2005, o Governo da Baixa Saxônia entendeu que os Municípios são instituições independentes e poderosas, cujo trabalho não precisa ser monitorado constantemente. Contudo, isso não foi colocado em prática, tendo em vista que uma das principais atividades dos governos distritais é a fiscalização do ente local. De acordo com Merk (2013, p. 4), o princípio reordena as tarefas entre os entes e compreende que se surgirem dificuldades a nível local, o ente superior deve intervir.

Sämtliche Aufgaben müssen dort erledigt werden, wo sie anfallen. Dabei auftretende Schwierigkeiten gilt es zunächst auf jener Ebene aus dem Weg zu räumen, in der sie auftauchen. Erst wenn dies nicht zu bewältigen ist, darf durch Hilfe „von oben" eingegriffen werden (positiv allgemein ausgedrückt: es wird damit der selbstverantwortliche Wirkungskreis des Einzelnen und der kleinen Sozialgebilde vor Bevormundung geschützt). ${ }^{3}$ (Merk, 2013, p. 4)

A partir disso, autores como Nipperdey (1980), elencam o lado positivo e negativo desse princípio - primeiro, o negativo descrito como uma barreira funcional e o positivo como uma ferramenta. De maneira mais explicativa, o bloqueio de função (lado negativo) significa que uma autoridade superior não pode arrastar uma tarefa para si, simplesmente porque seria melhor realizada por uma instância mais próxima ao cidadão, essa função de barreira serve para a proteção da autonomia e da autoridade local. De outra forma, no caso onde um Município não puder, por qualquer

3 Tradução livre: Todas as tarefas devem ser preenchidas onde elas são incorridas. Ao mesmo tempo, as dificuldades devem ser superadas ao nível em que ocorrem. Somente quando isso for superado, será permitido a intervenção "de cima" (positivamente expresso em termos gerais: Torna-se o círculo de ação autorresponsável do indivíduo e do indivíduo protegido pela pequena estrutura social antes paternalista). (Grifo nosso) 
razão que seja, realizar determinada tarefa ou cumprimento de alguma competência, então a autoridade superior deve prestar auxílio e intervir - esse seria a positividade da subsidiariedade como ferramenta. A posição dos entes federados e administrativos na Alemanha está disposta conforme a figura abaixo, na qual o círculo representa a estrutura da federação, onde é aplicada a subsidiariedade vertical.

A subsidiariedade tem orientado diversos processos de descentralização que estão ocorrendo nos países da América Latina, assim como o Brasil. O princípio da subsidiariedade pode ser levado como argumento para restringir ou conter a intervenção estatal, com um domínio de aplicação no Estado federal, como no Brasil, em que detém o Município como a entidade menor da federação com a capacidade de autogoverno de solução de questões que o afetam; e a repartição das competências, conforme já dispostas no capítulo anterior, em que a subsidiariedade revela que os entes federativos são subsidiários entre eles, em suas competências, de acordo com Carvalho (2008).

A Constituição Federal de 1988 integrou o Município como ente do Estado Federal Brasileiro, contudo o seu reconhecimento de autonomia ocorre desde a Constituição de 1891, em que colocava a organização dos Estados e assegurava a autonomia dos Municípios em tudo aquilo que fosse de seu interesse. Essa autonomia foi em grande parte tutelada pela União e pelos Estados no período republicano e, diante disso, Ferreira Filho (1997) considera que os Municípios foram a única entidade viva na colonização, no império e, em grande parte da existência da República, foi desenvolvido um estadualismo, que foi posteriormente substituído pela visão nacional político-administrativa.

De acordo com Almeida (2005), a federação no Brasil foi desenvolvida por uma estrutura tripla, de ordem central, estadual e municipal. Com a Constituição de 1988, conferiu-se a capacidade de organização, que até então não tinha uma previsão no ordenamento constitucional e isso determinou ainda a eleição para prefeito e vereadores, e incluiu uma nova repartição de receitas tributárias. Conforme o entendimento de Horta (2002b), quanto trata da pluralidade de ordenamentos jurídicos, o Brasil é no âmbito municipal em que se favorece a aplicação da subsidiariedade. O fortalecimento do Município, tanto para Medina (2002) quanto para Baracho (1997), demonstra preferência diante da descentralização de poderes e entende que é na esfera local que o indivíduo tem influencia diante do governo, o que propicia uma participação e fiscalização efetiva.

Conforme apresentado, a subsidiariedade se relaciona com o federalismo diante da organização das relações entre os entes, e os Municípios no Brasil são considerados entes menores com relação aos Estados e a União, que sempre serão o maior. 
Por isso que é formulada a concepção de que tudo que a comunidade local puder fazer por si mesma, deverá realizar, exceto quando for imprescindível de intervenção, em que a ação de preferência será do Estado ou da União. Na formação do princípio, diante do municipalismo, temos duas relações: uma diante da preferência da ação da comunidade em consonância ao Município e a preferência do Município diante das ações dos outros entes federativos. Assim, a subsidiariedade apresenta os limites para as ações do Estado em que não haja ingerência indevida deste na vida particular ou dos outros entes no Município. Nesse entendimento, Baracho (1997) expressa a ideia do federalismo relacionado com a subsidiariedade.

A Federação Brasileira revela a autonomia dos Municípios, conforme já mencionado, assim como a descentralização política, e tem relação com a subsidiariedade, entendida também como um critério delimitador de competências na federação, ou de divisão delas. A estrutura informa a interpretação destas nos governos locais, nas funções de interesse local. A Constituição de 1988 atribui aos Municípios a competência para legislar em assuntos que sejam de interesse local, restando apenas à interpretação do que seria o interesse local. Ainda, ao ser aplicado o princípio, o interesse local seria o que ensejaria atuações possíveis de serem feitas da melhor forma pelo governo local, e não por outro ente federativo.

A partir da ideia de que o Município pode realizar suas tarefas, ele deve então fazê-lo e será considerado como o interesse local. Uma contrariedade que poderia ser apresentada diz respeito à questão de que nem todos os Municípios tem a capacidade de fazer e então não haveria uma certa uniformidade, pois, nesse caso, alguns Municípios iriam fazer e aqueles que não fariam seriam assumidos pelos entes federativos superiores. Contudo, essa é a lógica do princípio que contempla a diversidade entre os Municípios, pois diante da realidade municipal, o ideal é a adequação das ações públicas com respeito a essa diversidade.

Esse princípio é tido como crucial para os governos locais, para que estes participem nacionalmente na busca por cidadania e soluções de interesse local, onde a participação ativa do cidadão deve ser realizada nos contextos político e social. Krell (2008) entende que a função relacional da subsidiariedade é aquela que obriga o poder do Estado a possibilitar e promover ações dos entes menores em prol do bem coletivo. Assim, para que a subsidiariedade seja alcançada, existe a necessidade de engajamento do Estado, de governantes e da comunidade, uma vez que o princípio somente se concretiza em âmbito local desde que o cidadão seja verificado como um concreto e não um abstrato, o que pode atingir uma democracia nesse espaço e permitir a inclusão social dos cidadãos, além de modificar também a própria visão de Estado. 
Entende-se que o motivo de o governo local atrair os atores sociais não está alicerçado no processo de uma comunicação mais efetiva, mas sim por um sentimento de pertencimento por parte destes. É essa sensação que faz com que se sintam pertencentes ao local em que vivem e participem diretamente e de forma eficaz, o que possibilita a interferência na elaboração e na aplicação das políticas inerentes, e faz acreditar que esta participação é efetiva. Conforme Hermany (2012), o princípio da subsidiariedade estimula o interesse público, seja por meio individual ou "corpos sociais intermediários" entre o cidadão e o Estado. Percebe-se a importância desse princípio para garantir que no âmbito local, por meio das políticas públicas, possa ocorrer a concretização da cidadania e da democracia. Ainda conforme o referido autor, Hermany (2012), os Municípios podem efetivar dimensões diferentes da subsidiariedade.

O exame do princípio da subsidiariedade leva em consideração a organização do princípio, por meio da qual as decisões devem ser adotadas no nível mais próximo dos indivíduos. Questiona-se o cabimento e a validade diante das dificuldades da descentralização do poder em setores que ultrapassam, muitas vezes, fronteiras nacionais. Da análise, observa-se que cabe aos Municípios o desenvolvimento e ajuste das diretrizes e normas elaboradas pelos outros entes. As competências municipais têm incidência em aspectos administrativos e financeiros, com limites constitucionais, e isso enseja em uma dificultosa identificação da subsidiariedade, pois nesse nível é onde se concentra o maior número de decisões até que atinja a sua capacidade.

A contribuição de Hermany (2012) no que tange a aplicação do princípio da subsidiariedade merece destaque, pelo fato de que aponta para um poder local em que este valorize o espaço municipal, com estrutura institucional próxima à sociedade e que não prescinda da articulação de princípios referenciais que servem como um freio institucional. Ainda, para a adoção da subsidiariedade internamente não é necessária uma idealização do âmbito local, pois considera-se que este deve estar condicionado aos princípios informativos do ordenamento jurídico. O ideal trazido pelo princípio poderia ser uma ferramenta para a reformulação do pacto federativo no Brasil, a ser utilizado na repartição de competências, sendo uma reforma possível de se realizar, já que não aboliria a forma federativa, mas sim reforçaria o pacto.

Além do mais, faz-se necessária a expressa definição da subsidiariedade no ordenamento constitucional, pois será um norteador das prioridades de cada ente para que as falhas na sistematização não venham a causar maiores entraves, como duplicação e superposições de serviços, responsabilidades administrativas, bem como excessos de burocracia. Ou seja, ao aplicar tal princípio, deve-se observar as questões peculiares do Brasil. A União deve centralizar apenas matérias de nível nacional e concentrar serviços que condizem com a soberania ou com a unidade econômica, como a questão da segurança pública e externa, relações exteriores ou mesmo com a 
unidade econômica, ou aqueles que não poderiam ser prestados senão pela centralidade. A flexibilidade da federação permite os reajustes que se mostram necessários, sem o perigo de causar uma asfixia nos Municípios.

\section{CONCLUSÕES}

A noção do princípio da subsidiariedade demonstra um modo específico de concepção e regulação de relações da vida do indivíduo na sociedade, como é o resultado das contribuições realizadas por Artistóteles, São Tomás de Aquino e Althusius. A individualidade do homem traz a justificação da organização social, que tem por base a realização do bem comum e deve garantir a autonomia do indivíduo e das coletividades, além de justificar a intervenção de um ente maior.

Nesse contraponto entre a autonomia e a intervenção, o princípio demonstra uma dimensão dupla: de forma negativa por meio do qual a maior comunidade deve se abster de agir quando a instância menor tem capacidade suficiente de atuação; e positiva, por meio da justificação da intervenção comunitária em busca do bem comum, seja porque o ente inferior se mostrou insuficiente ou porque o superior se mostra mais eficiente.

O princípio da subsidiariedade foi consolidado como um princípio em modalidade de organização diante do processo de integração da União Europeia e ganhou uma significação própria. Na Alemanha, a controvérsia sobre a aplicação de forma implícita do princípio tem origem na Lei fundamental de 1949, que perpassou o Tratado de Maastricht e ressurgiu o debate quanto à subsidiariedade. Posteriormente, uma modificação na Lei fundamental alterou a redação do artigo 23, que dispõe sobre a participação do Estado alemão na União Europeia, em que os Länder conseguiram manter a posição de participação e a expressa menção do princípio da subsidiariedade referindo-se somente ao plano externo. Sob o ponto de vista interno, a aplicação é controversa.

Dito isso, esse princípio constitui a essencialidade e se torna dependente da iniciativa da sociedade ao delimitar e legitimar a atuação do poder central, e tornar a aplicação no ordenamento do Brasil de grande valia, uma vez que fornece a direção para que sejam atingidos objetivos que são tratados na Constituição Federal de 1988, como a constituição de uma sociedade livre, solidária e justa, bem como a redução das desigualdades sociais e promoção do bem comum.

Esse princípio é conjugado por meio de medidas de incentivo para a cooperação entre os entes da federação, pois a centralização poderia ser moldada nesse reforço de cooperação, que também tem previsão constitucional, como os convênios de coo- 
peração e os consórcios públicos. Nesses institutos, o princípio da subsidiariedade poderia contribuir como critério para distribuição das atribuições de cada ente da federação.

Ao final, aponta-se ainda que diante da análise da subsidiariedade, o princípio se demonstra como crucial para os Municípios, para que estes possam participar em âmbito nacional na busca pela cidadania e por soluções de interesse local, onde resta evidente a importância da participação do cidadão nos contextos políticos e sociais. Para que isso seja alcançado, é necessário o engajamento de todos os atores políticos e sociais, pois o princípio somente se concretizará em âmbito local quando for verificado o cidadão como concreto e atingir uma democracia nesse espaço que permite a inclusão social de todos os cidadãos, além de modificar a visão do próprio Estado.

\section{REFERÊNCIAS}

Almeida, F. D. M. (2005) Competências na Constituição de 1998. São Paulo: Atlas.

Baracho, J. A. O. (1997). O princípio da subsidiariedade: conceito e evolução. Rio de Janeiro: Forense.

Berman, S. E. (2001). Modernization in historical perspective: the case of imperial Germany. World Politics 53(3), p. 431-462.

Bundesrepublik Deutschland (2018). Grundgesetz. Recuperado de https://www.bundestag.de/gg.

Carneiro, J. M. B.; Dill, G. (2012). Arranjos federativos regionais na Alemanha e o papel articulador dos Landkreise. Cadernos Adenauer XII,(4), p. 57-77.

Carvalho, K. G. (2008). Direito constitucional: teoria do Estado e da constituição, direito constitucional positivo. Belo Horizonte: Del Rey.

Clergerie, J. L. (1997). Le principe de subsidiarité. Paris: Elipses.

Ferreira Filho (1997). Comentários à Constituição Brasileira de 1988. São Paulo: Saraiva.

Ferraz, A. C. C. (1979). Poder constituinte do Estado-membro. São Paulo: Revista dos Tribunais.

Götz, V., Hecker, M. (1999). Il principio di sussidiarietà nel diritto constituzionale tedesco com particolare rifirimento allá sua dimensione federale. Em Rinella, A., Coen, L., Scarciglia, R. Sussidiarietà e ordinamenti constituzionali: esperienze a confronto (p. 102-132), Padova: CEDAM.

Gonçalves, V. M. N. (2003). Estado, sociedade civil e princípio da subsidiariedade na era da globalização. Rio de Janeiro: Renovar.

Hermany, R. (2012). Município na Constituição: o poder local na constitucionalismo luso-brasileiro. Curitiba: Juruá.

Hermany, R. (2005). O princípio da subsidiariedade e o direito social de Gurvitch: ampliação das competências municipais e a interface com a sociedade. Em Leal, R. G., Reis, J. R. Direitos sociais E políticas públicas. Desafios contemporâneos (p. 101 121). Santa Cruz do Sul: EDUNISC.

Horta, R. M. (2002a). Direito constitucional. Belo Horizonte: Del Rey. 
Horta, R. M. (2002b). Federalismo e o princípio da subsidiariedade. Em Martins, I. G. S. As vertentes do direito constitucional contemporâneo: estudos em homenagem a Manoel Gonçalves Ferreira Filho (p. 59-78). Rio de Janeiro: América Jurídica.

Hockerts, H. G. (1981). German post-war social policies against the background of the Beveridge Plan: Some observations preparatory to a comparative analysis. Em Mommsen, J. The emergence of the welfare state in Britain and Germany 1850-1950 (p. 198-210) London: Croom Helm.

Krell, A. (2008). Leis de normas gerais, regulamentação do Poder Executivo e cooperação intergovernamental em tempos de Reforma Federativa. Belo Horizonte: Fórum.

Maciel, O. S. (2004). Princípio de subsidiariedade e jurisdição constitucional. Belo Horizonte: Mandamentos.

Mello, C. D. A. (1996). Direito internacional da integração. Rio de Janeiro: Renovar.

Medina, P. (2002). O princípio da subsidiariedade. Em Martins, I. G. S. As vertentes do direito constitucional contemporâneo: estudos em homenagem a Manoel Gonçalves Ferreira Filho (p. 205-239). Rio de Janeiro: América Jurídica.

Merk, G. (2013). Das Subsidiaritätsprinzip. Recuperado de https://www.wiwi.uni-siegen.de/merk/ downloads/lehrmittel/subsidiaritaetsprinzip_definitionen.pdf.

Nipperdey, T. (1980). Der Föderalismus in der deutschen Geschichte. Em Boogman J.C., Van Der Plaat, G. N. Federalism (p. 159-179). Dordrecht: Springer.

Nunes, L. A. R. (2002). O princípio constitucional da dignidade da pessoa humana: doutrina e jurisprudência. São Paulo: Saraiva.

Palier, B. (2010). Continental Western Europe. Em Castles, F. G. The Oxford Handbook of the Welfare State (p. 203-232). Oxford and New York: Oxford U.P.

Quadros, F. (1995). O princípio da subsidiariedade no direito comunitário após o Tratado da União Européia. Coimbra: Almedina.

Van Kersbergen, K. (1995). Social Capitalism: A Study of Christian Democracy and the Welfare State. London: Routledge.

Zimmermann, A. (1999). Teoria geral do federalismo democrático. Rio de Janeiro: Lumen Juris.

Weber, A., Gas, T. (2000). Republique Fédérale d'Allemagne: justice constitucionnelle et subsidiarité. Em Delpérré, F. Justice constitutionnelle et subsidiarité (p. 137-177). Bruxelas: Bruylant. 